\title{
Beta-blockade in experimental fluid-resuscitated sepsis: acute haemodynamic effects of esmolol differ in predicted survivors and non-survivors
}

\author{
W Khaliq ${ }^{1 *}$, DT Andreis ${ }^{1,2}$, M Singer $^{1}$ \\ From ESICM LIVES 2015 \\ Berlin, Germany. 3-7 October 2015
}

\section{Introduction}

Beta-blockade therapy during sepsis has a sound rationale in view of its cardiac, metabolic, inflammatory and other effects [1]. Whether it is safe and efficacious in both good prognosis and poor prognosis patients is yet to be ascertained. We have developed a 72-h fluid-resuscitated rat model of faecal peritonitis, where prognosis can be accurately predicted as early as $6 \mathrm{~h}$ post-insult based on the degree of myocardial depression (low stroke volume, high heart rate)[2]. This model offers a useful means of testing safety and efficacy.

\section{Objectives}

To compare dose-related haemodynamic effects of esmolol at 6 hours in predicted survivors and non-survivors from faecal peritonitis.
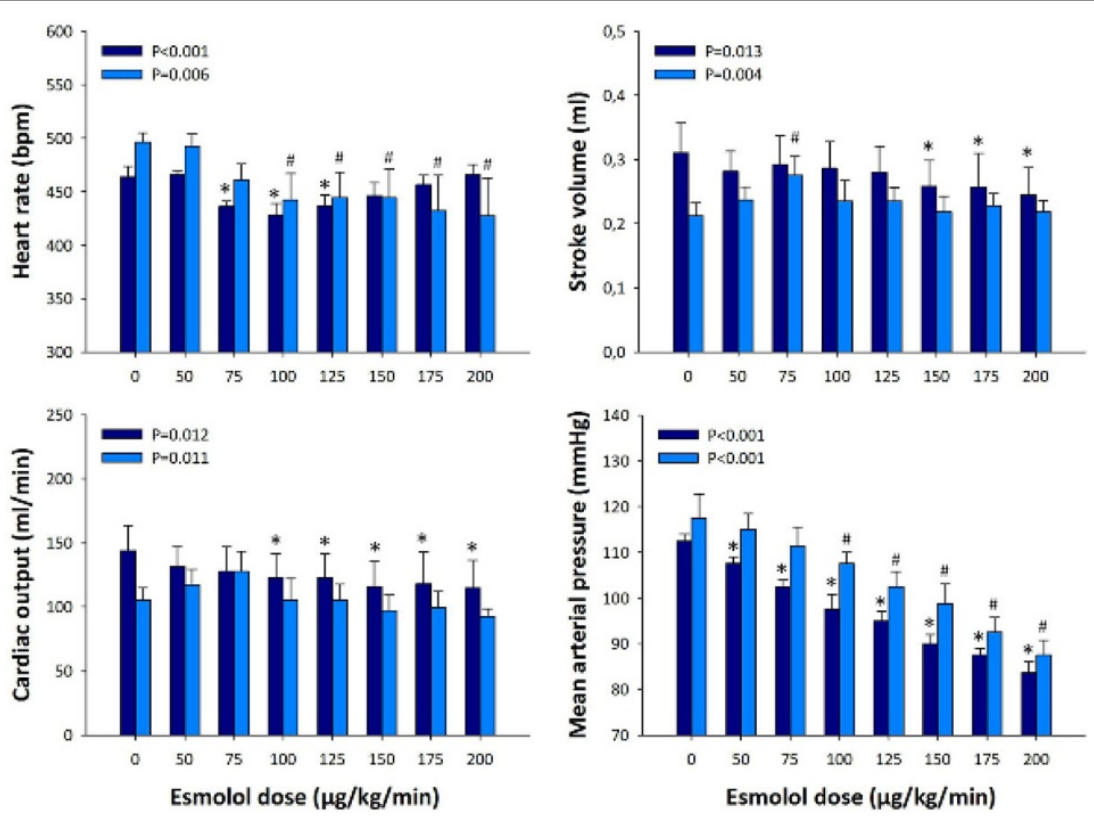

Figure $1 * p<0.05$ vs. baseline (good prognosis group, dark blue bars, $\mathrm{N}=4$ ). ${ }^{\#} \mathrm{p}<0.05$ vs. baseline (poor prognosis group, light blue bars, $N=4)$.

(c) 2015 Khaliq et al.; This is an Open Access article distributed under the terms of the Creative Commons Attribution License (http:// creativecommons.org/licenses/by/4.0), which permits unrestricted use, distribution, and reproduction in any medium, provided the original work is properly cited. 


\section{Methods}

Instrumented male Wistar rats $(350 \pm 16 \mathrm{~g})$ had sepsis induced with intraperitoneal injection of faecal slurry. Fluid resuscitation $(10 \mathrm{ml} / \mathrm{kg} / \mathrm{h})$ was begun $2 \mathrm{~h}$ later. At $6 \mathrm{~h}$, animals were divided into predicted survivors or non-survivors depending on a stroke volume cut-off of $0.20 \mathrm{ml}$. After an additional $10-\mathrm{ml} / \mathrm{kg}$ fluid bolus, esmolol was administered as a $500-\mu \mathrm{g} / \mathrm{kg}$ loading dose followed by an increasing stepwise infusion ( 50 to $200 \mu \mathrm{g} / \mathrm{kg} / \mathrm{min}$ in $25-\mu \mathrm{g} / \mathrm{kg} / \mathrm{min}$ increments 5 minutes apart). Heart rate, stroke volume and mean arterial pressure were recorded just prior to each dose increase. Repeated measures ANOVA and post-hoc Holm-Sidak test were used to seek statistically significant differences.

\section{Results}

Baseline stroke volume at $6 \mathrm{~h}$ was significantly lower in poor prognosis animals $(0.27 \pm 0.07$ vs. $0.18 \pm 0.02 \mathrm{ml}$, $\mathrm{p}<0.05)$. Stroke volume increased with low dose esmolol in predicted non-survivors, and this offset the reduction in heart rate (Figure 1). Cardiac output was thus maintained in predicted non-survivors but fell significantly in predicted survivors. Mean BP fell in parallel in both groups, though significant changes were seen earlier in predicted survivors.

\section{Conclusions}

Depending on their prognosis, septic rats show different haemodynamic responses to a short-term esmolol infusion at $6 \mathrm{~h}$ post-septic insult. Whether longer-term infusion is beneficial or harmful to these subgroups will be the subject of future study.

\section{Grant Acknowledgement}

ESICM Basic Science Award, UK Intensive Care Society Young Investigator Award, NIHR.

\footnotetext{
Authors' details

Published: 1 October 2015

\section{References}

1. Morelli A, et al: JAMA 2013, 310:1683-1691.

2. Rudiger A, et al: Clin Sci 2013, 124:391-401.
}

'University College London, Bloomsbury Institute of Intensive Care Medicine, London, United Kingdom. ${ }^{2}$ Università degli Studi di Milano, Dipartimento di Fisiopatologia Medico-Chirurgica e dei Trapianti, Milan, Italy.

doi:10.1186/2197-425X-3-S1-A801

Cite this article as: Khaliq et al:: Beta-blockade in experimental fluidresuscitated sepsis: acute haemodynamic effects of esmolol differ in predicted survivors and non-survivors. Intensive Care Medicine Experimental 2015 3(Suppl 1):A801.

\section{Submit your manuscript to a SpringerOpen ${ }^{\mathcal{O}}$ journal and benefit from:}

- Convenient online submission

- Rigorous peer review

- Immediate publication on acceptance

- Open access: articles freely available online

- High visibility within the field

- Retaining the copyright to your article

Submit your next manuscript at $>$ springeropen.com 